\title{
Limited English proficiency and psychological distress among Latinos and Asian Americans
}

\author{
Wei Zhang ${ }^{a},{ }^{*}$, Seunghye Hong ${ }^{\mathrm{b}}$, David T. Takeuchic, and Krysia N. Mossakowski ${ }^{\mathrm{a}}$ \\ aDepartment of Sociology, The University of Hawaii at Manoa, Honolulu, HI, USA \\ bSchool of Social Work, The University of Hawaii at Manoa, USA \\ 'School of Social Work and Department of Sociology, The University of Washington, USA
}

\section{Abstract}

English proficiency is increasingly recognized as an important factor that is related to the mental health of immigrants and ethnic minorities. However, few studies have examined how the association between English proficiency and mental health operates and whether the pattern of association is similar or different among various ethnic minority groups. This paper investigates how limited English proficiency directly and indirectly affects psychological distress through pathways of discrimination for both Latinos and Asian Americans in the United States. Findings suggest that, for Asian Americans, limited English proficiency has an independent relationship with psychological distress over and above demographic variables, socioeconomic and immigration-related factors and discrimination. For Latinos, however, socio-demographic variables and discrimination show a stronger association than limited English proficiency in affecting psychological distress. Different forms of discrimination - everyday discrimination and racial/ethnic discrimination - are equally important for both ethnic groups. Findings underscore the differential role of limited English proficiency for the mental health of Asian Americans and Latinos and suggest the distinctive racial experiences and backgrounds of these two ethnic groups.

\section{Keywords}

English proficiency; Discrimination; Psychological distress; Latinos; Asian Americans; USA; Language

\section{Introduction}

The upsurge in immigrants in recent decades and the subsequent growth of the foreign-born population in the United States have led to a high proportion of people with a low level of English proficiency. Kim, Loi, et al. (2011), drawing on U.S. Census data, found that over $51 \%$ of the U.S. immigrant population reported speaking English less than "very well" and they were referred to as a population with limited English proficiency (LEP). LEP is particularly an issue for Latinos and Asian Americans because they constitute approximately 78\% of the foreign-born population since 2000 (Camarota, 2007; Hall \& Farkas, 2008).

English proficiency is a primary social status variable for immigrants and their children because it is closely associated to socioeconomic factors (i.e., earning and employment status), social interactions, and discrimination (Gee, Walsemann, \& Takeuchi, 2010). As

(c) 2012 Elsevier Ltd. All rights reserved.

*Corresponding author. Tel.: +1 510717 9837. weizhang@ hawaii.edu (W. Zhang). 
Jasso (2011, p.1328) remarked, "Perhaps no single characteristic is as emblematic of both the life chances of immigrants and their children and the reactions of natives as English fluency." Proficiency in the host country's language plays a significant role in the economic assimilation of immigrants and their children (Casey \& Dustmann, 2008). There is empirical evidence suggesting a positive association between English skills and earnings for immigrants (i.e., Bleakley \& Chin, 2004; Hall \& Farkas, 2008). LEP or speaking English with an accent is usually associated with a foreigner stereotype and can trigger discrimination (i.e., Bleakley \& Chin, 2004; Gee \& Ponce, 2010).

LEP is increasingly recognized as one of the key correlates of health behaviors (Tang, Shimizu, \& Chen, 2005), self-rated general health (Ding \& Hargraves, 2009; Gee et al., 2010; Ponce, Hays, \& Cunningham, 2006), physical health (Kim, Worley, et al., 2011), mental health (Kim, Wang, Deng, Alvarez, \& Li, 2011; Kim, Worley, et al., 2011; Ponce et al., 2006; Torres, 2010), health-related quality of life (Gee \& Ponce, 2010; Mui, Kang, Kang, \& Domanski, 2007) and health service access and utilization (Kim, Loi, et al., 2011; Kim, Worley, et al., 2011; Ponce et al., 2006; Shi, Lebrun, \& Tsai, 2009) for American immigrants, Asian Americans in particular. These past associations with health outcomes are probably due to its links with both economic and social factors.

To date, however, only a limited number of studies (Ding \& Hargraves, 2009; Kim, Wang, et al., 2011) examine how the association between English proficiency and mental health operates. Even fewer studies, if any, compare this association among different racial and ethnic minorities using representative samples. The current study elaborates and tests hypotheses regarding how LEP is directly and indirectly associated with psychological distress through pathways of discrimination. We compare the patterns of the association between Latinos and Asian Americans, the two large racial/ethnic minority groups that are most likely to face English language difficulties.

\section{Theoretical background}

\section{The direct effect of LEP on psychological distress}

As one of the first steps toward acculturation to the United States (Gordon, 1964) and an essential requirement for upward social mobility, English proficiency can be considered as an important social status variable that directly influences patterns of psychological distress. If immigrants are unable to comprehend or speak English, it can create a "cultural distance" (Berry, 1997). For instance, LEP can make it difficult for a person to communicate with others, develop social networks with English-speaking residents, and access useful information, which may seriously undermine life chances. All of these inconveniences and discomforts in the navigation of daily life may be stressful and eventually lead to negative emotions such as frustration, sadness, anxiety, and a sense of insecurity, which in turn, will directly boost levels of psychological distress. New immigrants who have lived in the country for a short duration and who have LEP could be especially at risk of experiencing this type of "acculturative stress" because they have not yet adapted to the dominant culture, which has negative psychological ramifications (Berry, 1997). In this sense, LEP itself is a social vulnerability and an acculturative stressor that increases levels of psychological distress through an independent effect.

Accordingly, the first aim of this study is to examine the direct effect of LEP by answering the following research question: Do Latinos or Asian Americans with LEP (i.e., individuals whose spoken English is other than excellent or good) tend to report poorer mental health indicated by higher levels of psychological distress? According to the existing theories and empirical evidence on social status, acculturation, and mental health, we expect to identify a 
positive association between LEP and psychological distress for both Latinos and Asian Americans.

\section{The indirect effect of LEP on psychological distress}

Levels of English proficiency may influence other factors to indirectly affect psychological distress. Individuals with LEP can become wary that they are being victimized or stigmatized as a result of their difficulties with language and communication or worry about interpersonal discomfort and embarrassment that could lead to social isolation, undermine self-worth, and eventually cause negative psychological consequences (Mui et al., 2007). Among various psycho-social factors, perceived discrimination may be an important mediating factor that links LEP and mental health, but it has not been closely examined by previous studies. Using the California Health Interview Survey, Gee and Ponce (2010) found that LEP and perceived discrimination are both independently associated with poorer quality of life. Although this study simultaneously examined LEP and discrimination, it did not directly test the mediating effect of discrimination. Kim, Wang, et al. (2011) conducted the very first study to examine the mechanisms linking LEP with mental health through discrimination. Using a sample of Chinese American adolescents, Kim et al. found that low levels of English proficiency in middle school were related to speaking English with an accent in high school, which in turn, contributed to the perception of being stereotyped as a perpetual foreigner, discriminatory experiences, and depressive symptoms. However, one of the limitations of this study was the use of a regional sample composed exclusively of Chinese Americans.

How would LEP influence mental health through discrimination? LEP or speaking English with an accent may greatly hinder interpersonal communications and directly invoke racial stereotypes and biases that lead to discrimination (Kim, Wang, et al., 2011; Yoo, Gee, \& Takeuchi, 2009). Self-reported experiences of discrimination have been found to be associated with poorer mental health for both Latinos (Araujo \& Borrell, 2006; Finch, Kolody, \& Vega, 2000; Torres \& Ong, 2010) and Asian Americans (Gee, Spencer, Chen, Yip, \& Takeuchi, 2007; Hahm, Ozonoff, Gaumond, \& Sue, 2010; Mossakowski, 2003; Yip, Gee, \& Takeuchi, 2008). On the other hand, however, it is also possible that individuals with LEP are not sensitive toward discrimination because of the language barrier, and thus underreport discrimination. Finch et al. (2000) revealed that more highly acculturated Mexican immigrants (i.e. those with greater usage of English and longer durations of U.S. residence) are more likely to perceive discrimination compared to their less acculturated counterparts. Similarly, Perez, Fortuna, and Alegria (2008) found that American-born Latinos and Latinos arriving in the U.S. at younger ages are more likely to perceive discrimination than immigrants arriving at older ages.

Taken together, the second aim of this study is to explore the indirect effect of LEP on psychological distress by answering the following research question: Can the association between LEP and psychological distress be attributed to discrimination? We propose that LEP will be positively related to different forms of discrimination, which in turn, are positively associated with psychological distress (Fig. 1). However, we should recognize the aforementioned possible negative association between LEP and perceived discrimination. Individuals with LEP may underreport discrimination due to reasons such as residential isolation and lower levels of exposure and sensitivity.

When examining the effect of discrimination, we consider everyday discrimination (Williams, Yu, Jackson, \& Anderson, 1997) and racial/ethnic discrimination, two distinct but embedded dimensions of stressful experiences. Essentially, everyday discrimination includes more of the generic, chronic and minor forms of unfair treatment that largely involve "character assaults" (Kessler, Mickelson, \& Williams, 1999), whereas racial/ethnic 
discrimination is an acute and major experience of unfair treatment that is specifically due to one's race and ethnicity, and critical to one's social mobility. As a chronic stressor, everyday discrimination is closely related to acute racial/ethnic discrimination. For instance, a person may become exposed to more episodes of chronic unfair treatment after experiencing job loss or denial of a bank loan due to his/her race and ethnicity. According to previous studies (e.g., Kessler et al., 1999; Mossakowski, 2003; Williams et al., 1997; Williams, Spencer, \& Jackson, 1999), everyday discrimination has a more powerful and harmful effect on mental health than acute racial/ethnic discrimination because it is a chronic stressor.

\section{Methods}

\section{Sample}

Our data are drawn from the 2002-2003 National Latino and Asian American Study (NLAAS), a nationally representative household survey of Latino and Asian Americans. This survey used a stratified area probability sample design and involves three major steps of sampling (Heeringa et al., 2004). The first step was the core sampling: city or contiguous census blocks were selected according to population density; then, housing units were sampled within each block and one adult was sampled within each selected housing unit. The second step was the supplementary sampling: census blocks with greater than 5\% of the target population were over-sampled. In order to further enlarge the sample size, the third step was applied to recruit the secondary respondents from previously sampled households where a primary respondent had already been interviewed. The face to face interview was administered by bilingual lay interviewers, and respondents were allowed to choose their favorite languages.

Subjects of the NLAAS study were non-institutionalized people of Latino or Asian ancestry who were 18 years of age or older and resided in any of the 50 states or Washington DC. A total of 2095 Asian American and 2554 Latino participants were recruited between May 2002 and November 2003. Asian Americans reported themselves as Chinese $(n=600)$, Filipino $(n=508)$, Vietnamese $(n=520)$, and Other Asian $(n=467)$. The "Other Asian" category includes individuals who identified as Japanese, Korean, Asian Indian, and other. Mexican ( $n=868)$, Puerto Rican $(n=495)$, Cuban $(n=577)$, and "Other Latino" $(n=614)$ were the four main subgroups of the Latino sample. Individuals from the "Other Latino" category reported numerous groups as their main origins, and each group had small sample sizes, mostly fewer than 3 respondents. The final weighted response rate for the Asian American sample was $65.6 \%$, and the rate for the Latino sample was $75.5 \%$. Slightly over $1 \%$ of the cases were excluded due to missing values, resulting in a final analytical sample of size 2072 for Asian Americans and 2526 for Latinos.

The University of Hawaii Committee on Human Studies approved this study as exempt from federal regulations pertaining to the protection of human research participants (Code of Federal Regulations at 45 CRF 46(4)).

\section{Dependent variable}

The Kessler Psychological Distress Scale (K10) was used to measure psychological distress. The K10, consisting of 10 questions, is considered a simple and valid measure of mental health (Furukawa, Kessler, Slade, \& Andrews, 2003) and has been used to assess the mental health of ethnic minorities such as Asian Americans (Walton \& Takeuchi, 2010; Yip et al., 2008) and Latinos (Rivera et al., 2008). Respondents were asked to indicate the frequency (1 $=$ all of the time, $2=$ most of the time, $3=$ some of the time, $4=$ a little of the time, and $5=$ none of the time) in the past 30 days with which they had experienced symptoms of depression and anxiety (e.g., tiring out, nervousness, hopelessness, restlessness, depression, 
sadness, worthlessness, and everything takes effort). All items were reverse-coded such that higher scores reflect higher levels of psychological distress. The average index of psychological distress demonstrates a strong internal consistency, as the values of a reliability are .88 and .91 for Asian Americans and Latino respondents, respectively. This variable was $\log$ transformed (Range $=.00$ to $1.48, M=.26, \mathrm{SD}=.29$ for Asian Americans; Range $=.00$ to $1.61, M=.28, \mathrm{SD}=.34$ for Latinos) in regressions because it was positively skewed for both Asian American (Skewness = $2.00(.001)$, Kurtosis $=5.04(.002))$ and Latinos (Skewness $=2.22(.001)$, Kurtosis $=5.72(.001)$ ).

\section{Independent variable}

The focal independent variable, LEP, was assessed by the question, "How well do you speak English?" Consistent with prior research (e.g., Kim, Loi, et al., 2011; Kim, Worley, et al., 2011), the response categories were dichotomized to contrast respondents with fair or poor English (coded as 1) to those with excellent or good English (coded as 0). Among the sampled respondents, $48.78 \%$ of Latinos and $33.70 \%$ of Asian Americans self-reported their English as being fair or poor. Prior research (Gee et al., 2010) suggests that using a categorical approach to measure LEP has an advantage in interpretation if reasonable cutoff points are used. We chose to use a cutoff point that is consistent with the literature. Our supplementary results also indicate that keeping English proficiency as a continuous variable yields similar results.

\section{Mediating variables}

One of our mediating variables is everyday discrimination, assessed using a 9-item index adopted from the Detroit Area Study (Williams et al., 1997). The items measure the frequency $(1=$ never to $6=$ almost everyday $)$ of chronic, routine, and minor experiences of unfair treatment. The nine items include: (1) "You are treated with less courtesy than other people," (2) "You are treated with less respect than other people," (3) "You receive poorer service than other people at restaurants or stores," (4) "People act as if they think that you are not smart," (5) "People act as if they are afraid of you," (6) "People act as if they think that you are dishonest," (7) "People act as if you are not as good as they are," (8) "You are called names or insulted," and (9) "You are threatened or harassed." An average index ( $\alpha=$. 91 for both Asian Americans and Latinos), ranging from 1 to 6, was computed with higher values indicating higher levels of everyday discrimination. Asian Americans $(M=1.81)$ and Latino $(M=1.82)$ shared similar mean levels of everyday discrimination.

Another mediating variable is racial/ethnic discrimination, which is assessed by three 4point scale $(1=$ never, $2=$ rarely, $3=$ sometimes, $4=$ often $)$ questions, developed by Vega, Zimmerman, Gil, Warheit, and Apospori (1993): (1) "How often do people dislike you because of your race/ethnicity?" (2) "How often do people treat you unfairly because of your race/ethnicity?" and (3) "How often have you seen friends treated unfairly because of their race/ethnicity?" An average index ( $a=.86$ for Asian Americans and $a=.81$ for Latinos), ranging from 1 to 4 , was created with higher scores reflecting a higher frequency of racial/ethnic discrimination. Compared to Asian Americans $(M=1.72)$, Latinos $(M=$ 1.82) reported a higher level of racial/ethnic discrimination.

\section{Control variables}

The first set of control variables includes SES factors such as education (less than high school, high school, some college, and college or more), annual household income (< $\$ 15,000, \$ 15,000-\$ 34,999.9, \$ 35,000-\$ 74,999.9$, and $\$ 75,000$ or more), and employment status (employed, unemployment, and not in labor force). The second set of control variables includes immigration-related factors such as citizenship (U.S.-citizenship $=1)$ and immigration status. Immigration status was divided into four categories: U.S.-born; 
immigrant, duration $=0-4$ years; immigrant, duration $=5-10$ years; immigrant, duration $\geq$ 11 years). We also controlled for demographic variables including gender (female $=1)$, age (in years), marital status (married/cohabiting, never married, divorced/separated/widowed), and several dichotomous variables for Asian groups (Vietnamese, Chinese, Filipino, and Other Asian Americans) and Latino groups (Mexican, Cuban, Puerto Rican, and Other Latinos).

\section{Analytical strategies}

SUDAAN, software for the statistical analysis of correlated data, was used to adjust for the effect of the complex study design of NLAAS. For both Asian American and Latino samples, the weighted descriptive statistics for the entire sample and sub-samples stratified by levels of English proficiency are summarized in Table 1. Following this, the primary analyses were conducted by estimating five Ordinary Least Squares (OLS) regressions to test the direct and indirect effects of LEP on psychological distress for both samples (Tables 2 and 3). To abide by the normality assumption of the OLS regressions, a log transformed psychological distress scale was used as the dependent variable due to the positive skewness of the original variable. In Models 1-2, LEP was included to examine its direct effect on psychological distress without and then with an adjustment for SES, immigration-related variables and demographic characteristics. Everyday discrimination and racial/ethnic discrimination were then included into Models 3-4 separately and jointly in Model 5 to examine if they mediate any effect of LEP on psychological distress. The reduction in the effect and significance level (Baron \& Kenny, 1986) of LEP on psychological distress in Models 3-5 will indicate a mediating effect for the discrimination variables.

\section{Results}

Table 1 shows noticeable differences in demographic variables, SES, immigration-related factors, racial/ethnic discrimination, psychological distress and levels of English proficiency for Asian Americans and Latinos by comparing the descriptive statistics for the whole samples. For the Asian American sample, more than half of the respondents were female $(52.74 \%)$ and most of them were married (65.28\%) and employed (64.09\%). Slightly less than one fourth of the respondents (22.98\%) were U.S.-born, but over $50 \%$ of the respondents reported a duration of residence in the U.S. being at least 11 years. Over two thirds of Asian respondents were U.S. citizens and 66.30\% reported speaking English either excellent or good. In terms of education and income, $67.42 \%$ reported having at least some college level of education and over $40.32 \%$ having an annual household income of at least $\$ 75,000$. Almost $29 \%$ were Chinese, and $12.84 \%, 21.56 \%$, and $36.89 \%$ were Vietnamese, Filipino, and other Asian Americans, respectively. Compared to Asian Americans, Latinos were younger and less likely to be married, and reported much lower levels of education, household income and English proficiency despite that they were more likely to be born in the United States. They were comparable with Asian Americans in employment status and everyday discrimination, but they reported slightly higher levels of racial/ethnic discrimination and psychological distress. Over half of the Latino sample was Mexican (56.41\%) compared to $4.66 \%, 10.04 \%$, and $28.89 \%$ of the sample being Cuban, Puerto Rican, and other Latino, respectively.

The Asian and Latino samples were then stratified by levels of English proficiency in Table 1. Results suggest that Asian Americans with LEP were more likely to be Chinese, Vietnamese, females, the married and individuals with lower levels of education and household income. Compared to Asian Americans with EP, Asian Americans with LEP reported higher levels of psychological distress (1.44 vs. 1.32, $t=5.28, p<.001)$ and racial/ ethnic discrimination (1.76 vs. 1.70, $t=1.94, p=.053)$, but a much lower level of everyday 
discrimination (1.62 vs. 1.91, $t=-8.50, p<.001)$. Latinos with LEP were more likely to be Mexican, immigrants, the married, the non-U.S. citizens, and individuals with lower levels of education and household income. Compared to Latinos with EP, Latinos with LEP reported a significantly lower level of everyday discrimination (1.62 vs. 2.02, $t=-11.85, p$ $<.001)$ but similar levels of racial/ethnic discrimination and psychological distress.

\section{Direct and indirect effect of LEP on psychological distress for Asian Americans}

To examine the direct and indirect effect of LEP, five sequential OLS regressions (Models 1-5) were estimated in Table 2 for Asian Americans. As expected, LEP $(b=.07, p<.001)$ was significantly associated with higher levels of psychological distress in Model 1 . The effect of LEP remained substantial $(b=.08, p<.001)$ in Model 2 after controlling for a wide range of SES and immigration-related factors and demographic variables. These findings indicate the strong and direct effect of LEP on psychological distress for Asian Americans. Model 2 also suggests that, compared to the Vietnamese, the Chinese reported a significantly higher level of distress $(b=.11, p<.001)$. Respondents who were currently married reported a lower level of distress than the never married individuals $(b=-.09, p<$. $01)$. No significant differences in psychological distress were found by any SES variables and immigration-related factors.

Everyday discrimination was found to be significantly associated with higher levels of distress $(b=.10, p<.001)$ in Model 3. Similarly, Model 4 reveals that having experienced racial/ethnic discrimination also has positive effects on distress $(b=.07, p<.001)$. When both measures of discrimination were included in Model 5 , the effect of everyday discrimination remained largely intact but the effect of racial/ethnic discrimination was attenuated by approximately $57 \%((.07-.03) / .07 \approx 57 \%)$ and approached significance at the $p=.05$ level. One possible explanation is that the effect of the more acute racial/ethnic discrimination is partially accounted for by the experience of more general and chronic unfair treatment. This finding is consistent with previous studies (Kessler et al., 1999; Mossakowski, 2003; Williams et al., 1997, 1999). Both the effect and significance level of English proficiency remain almost the same in Model 5, suggesting that measures of discrimination are not able to mediate any of its effect on distress as hypothesized. For Asian Americans, therefore, LEP was found to have a strong independent effect on psychological distress over and above perceived discrimination of any form, demographic variables, SES, and immigration-related factors.

\section{Direct and indirect effects of LEP on psychological distress for Latinos}

For Latinos, however, Models 1-2 of Table 3 suggest that demographic variables, SES and immigration-related factors are more important correlates of psychological distress than LEP. Its effect was found to be insignificant. For instance, females (compared to males) were significantly more likely to report higher levels of distress $(b=.07, p<.001)$. The employed showed much lower levels of distress $(b=-.10, p<.001)$ compared to the unemployed. Higher education, college or more levels of education in particular, suggests a significant mental health benefit. Latinos who are U.S. citizens showed significantly higher levels of distress $(b=.05, p<.01)$ in comparison with the non-U.S. citizens. Household income and immigration status, however, are not significantly associated with distress. Models 3-5 reveal that both everyday discrimination $(b=.11, p<.001)$ and racial/ethnic discrimination $(b=.08, p<.001)$ are significantly and substantially associated with distress and the former mediated approximately $50 \%((.08-.04) / .08 \approx 50 \%)$ of the effect of the latter. 


\section{Discussion}

This study reveals that the associations between LEP and psychological distress are different for Asian Americans and for Latinos in the United States. LEP plays a relatively unimportant role in relating to psychological distress for Latinos, whereas other factors including ethnicity, gender, education, citizenship, and discrimination are more significant correlates of distress for this ethnic group. For Asian Americans, however, both LEP and discrimination are associated with psychological distress and these associations remain when we adjusted for socio-demographic variables and immigration-related factors. Demographic and socioeconomic factors are less important correlates of distress for Asian Americans.

The distinctive patterns between Latinos and Asian Americans have several implications. First, these differences may indicate the differential racial experiences of these two groups. For Asian Americans, there might be a confluence of language with stereotypes of "perpetual foreigner." Lack of English abilities or speaking English with a nonstandard American accent is an important marker of foreignness, which in turn, contributes to more discriminatory treatment (Kim, 1999; Uba, 2002), racial/ethnic discrimination in particular, and an escalated level of distress. For Latinos, discrimination itself may capture the total "ethnic" experience that is more than language per se. Accordingly, our findings indicate that although both Asian Americans and Latinos are usually stereotyped by the public discourse as inherently foreigners (compared to the insiders-Whites and Blacks), they are labeled this way for different reasons. Limited English proficiency is a stigmatizing marker for Asian Americans that is psychologically distressing, but not for Latinos.

Another implication of the differential patterns suggests that maintaining Spanish in the process of acculturation may be more important than simply being fluent in English alone in promoting mental health for Latinos because maintaining Spanish may indicate closer relationships with one's ethnic enclaves and extended families. One study suggests that bilingualism indicated by both English proficiency and Spanish language use may have a positive impact on acquiring the institutional support that is necessary for social mobility in a school setting (Stanton-Salazar \& Dornbusch, 1995). Another study (Mulvaney-Day, Alegria, \& Sribney, 2007) reveals that Spanish/English bilingualisms (indicated by speaking good or excellent Spanish along with thinking all or some of the time in English) have a strong and positive effect on self-rated mental health for Latinos. As Mulvaney-Day et al. (2007, p.480) summarized, "The healthful effects of maintaining Spanish may depend upon how well the Spanish-speaker also speaks English, but that English-speaking alone may not indicate the greatest access to healthful connections and resources."

Given that both Latinos and Asian Americans have substantial within-group variations, we conducted follow-up supplementary data analysis (not shown but available upon request) to explore if the LEP-and-distress association differs across different Asian and Latino subgroups. Findings indicate that, except for Vietnamese (probably due to their small sample size in NLAAS), the focal association holds strongly for Filipino, Chinese, and other Asian Americans. For Latinos, however, the association is insignificant for Cubans, Puerto Ricans, and other Latinos. Although the focal association is significant for Mexicans, the negative coefficient of LEP suggests that it is associated with a decreased rather than an increased level of psychological distress. This finding challenges the assumption that acculturative stress decreases as level of acculturation increases and suggests that higher levels of English proficiency may be associated with Spanish competency pressure for Mexicans. This supplementary analysis further illustrates the importance of bilingualism and maintaining Spanish language proficiency for Latinos. When we examine language proficiency, as Rodriguez, Myers, Mira, Flores, and Garcia-Hernandez (2002) recommend, 
we should simultaneously assess both English proficiency (the language of host country) and ethnic language competence (the language of the original country) in future studies. Sometimes, the conflict of language competence can be likewise stressful for both immigrants and their children.

Why is LEP a key factor in understanding the mental health for Asian Americans but not for Latinos? In contrast to Asian languages, Spanish is considered to be the second language in the United States because it has proliferated. Therefore, it may be socially and psychologically easier for Latinos to navigate their daily contexts without an excellent level of English proficiency. Also, Asian Americans, on average, have high levels of education and many received their primary education (before age 16) in their home countries (Walton, Takeuchi, Herting, \& Alegria, 2009). After a well-educated upper-middle class Asian American immigrates to the U.S. with ambitious expectations, a stressful feeling of relative deprivation may be triggered by communication difficulties that could then lead to loss of face and a weakened sense of self-worth, which in turn, may increase levels of distress. For Latinos, however, immigrating to the U.S. may indicate more economic opportunities on average and they may not feel as relatively deprived. For Latinos, the frustration associated with English inability may be greatly compensated for by the improved economic conditions and the potential for upward social mobility relative to their country of origin.

Latinos and Asian Americans may also be very different in terms of residential and occupational structures. For Latinos who may primarily live within their ethnic enclaves and have jobs requiring less contact with American society, English proficiency may be seen as largely irrelevant because their social and emotional support may be more rooted in their ethnic communities. For Asian Americans who seek to integrate with the host community and have professional and managerial occupations, excellent English proficiency becomes critical and a lack of it may cause considerable difficulties and frustration, which will eventually take a toll on their psychological well-being. One study by Huang and Spurgeon (2006), examined the mental health status of Chinese immigrants in Birmingham, U.K. and discovered that variation in mental health among Chinese people was closely related to their degree of adjustment to the host society, which in turn, varied by immigrants' motivations, social and educational background, employment characteristics and reasons for migration. Their findings along with ours suggest that the differential importance of English proficiency for the mental health of Latinos and Asian Americans may be largely due to their differences in backgrounds.

The education-and-distress association is also quite different between Asian Americans and Latinos. This finding is consistent with previous studies that likewise found no association between education and mental health among Asian American groups (Leu et al., 2008; Mossakowski, 2003). Several speculations can be put forth to explain why this might be the case. As we mentioned previously, although the majority of Asian Americans have high levels of education, they have often received their primary education outside the United States. One of the previous studies by Zeng and Xie (2004) found that place of education plays a consequential role in the social stratification of Asian Americans. According to them, foreign-educated Asian immigrants earn approximately 16\% less than U.S.-born whites, U.S.-born Asian Americans, and U.S.-educated Asian immigrants. As a result, being educated in a foreign country may not lead to the same health payoffs as schooling received in the U.S. due to its limited economic returns. For example, Walton et al. (2009) revealed that the educational gradient in self-rated health is attenuated among Asian Americans, and place of education conditions the education-and-health relationship, such that being educated in a foreign country does not result in the same physical health payoffs for increasing educational attainment. 
Besides the aforementioned disparities, these two racial/ethnic groups also share some similar findings. For both Latinos and Asian Americans, the bivariate findings in Table 1 suggest that, in comparison with respondents with LEP, respondents with EP reported a significantly higher level of everyday discrimination but a slightly lower level of racial discrimination. This finding is consistent with some of the previous studies on Latino adolescents and Mexican Americans (Finch et al., 2000; Vega \& Gil, 1998) and Chinese Americans (Hwang \& Myers, 2007), indicating that individuals with low mastery of English may be either residentially isolated to have limited contact with American society or be less aware of cultural nuances and subtle discriminatory interactions. In this sense, the seemingly lower level of everyday discrimination reported by individuals with LEP may be somehow misleading because individuals with LEP may underestimate their experiences of discrimination due to limited daily contacts and the language barriers. Although respondents with EP reported significantly higher levels of everyday discrimination, they showed similar (for Latinos) or even lower levels (for Asian Americans) of psychological distress compared to those with LEP. This finding suggests that those with good/excellent English skills may be more resilient to the effects of discrimination and are better able to cope with the stress associated with discrimination due to enhanced economic and psychosocial resources such as a secure and well-paid job, a strong sense of personal control, and an enlarged and supportive social network.

In spite of these intriguing findings, this study should also be viewed in light of several limitations. First, our data are cross-sectional in nature and lack other important psychosocial variables. To disentangle a variety of mechanisms whereby LEP at Time 1 might causally predict psychological distress at Time 2, future longitudinal research encompassing variables gauging individual psychosocial status and health behaviors are greatly needed. In addition, LEP should also be viewed dynamically because language ability is usually a function of practices and acculturation. Future studies may examine how an improvement in English proficiency predicts changing levels of perceived discrimination and psychological distress. Second, our data also heavily relied on self-reports that may contain variability because of idiosyncratic interpretations of survey questions by respondents. Some respondents may overestimate their levels of English proficiency because of social desirability issues. Some respondents may underestimate levels of discrimination due to LEP. The subjective reporting of distress symptoms may also be greatly influenced by cultures, values, social location, current experiences, and health status. All these response biases may, to some extent, distort our findings. Third, some omitted but important variables on access and utilization of health services should be included in future studies to further disclose the important correlates of mental health for both ethnic groups.

Nevertheless, this study is the first one to comprehensively examine the direct and indirect effect of LEP on psychological distress through pathways of discrimination and compares the patterns between two of the largest minority groups in the United States, using nationally representative samples. Our findings underscore the differential role of English proficiency in relating to mental health for Asian Americans and Latinos, which suggest the potential distinctive racial experiences and backgrounds of these two ethnic minority groups.

\section{References}

Araujo BY, Borrell LN. Understanding the link between discrimination, mental health outcomes, and life chances among Latinos. Hispanic Journal of Behavioral Science. 2006; 28(2):245-266.

Baron RM, Kenny DA. The moderator-mediator variable distinction in social psychological research: Conceptual, strategic, and statistical considerations. Journal of Personality and Social Psychology. 1986; 51(6):1173-1182. [PubMed: 3806354] 
Berry JW. Immigration, acculturation, and adaptation. Applied Psychology: An International Review. 1997; 46(1):5-68.

Bleakley H, Chin A. Language skills and earnings: evidence from childhood immigrants. The Review of Economics and Statistics. 2004; 86(2):481-496.

Camarota, SA. Immigrants in the United States, 2007: A profile of America's foreign-born population. Center for Immigration Studies; 2007.

Casey T, Dustmann C. Intergenerational transmission of language capital and economic outcomes. The Journal of Human Resources. 2008; 43(3):660-687.

Ding H, Hargraves L. Stress-associated poor health among adult immigrants with a language barrier in the United States. Journal of Immigrant and Minority Health. 2009; 11(6):446-452. [PubMed: 18941893]

Finch BK, Kolody B, Vega WA. Perceived discrimination and depression among Mexican-origin adults in California. Journal of Health and Social Behavior. 2000; 41(3):295-313. [PubMed: 11011506]

Furukawa TA, Kessler RC, Slade T, Andrews G. The performance of the K6 and K10 screening scales for psychological distress in the Australian national survey of mental health and well-being. Psychological Medicine. 2003; 33(2):357-362. [PubMed: 12622315]

Gee GC, Ponce N. Associations between racial discrimination, limited English proficiency, and healthrelated quality of life among 6 Asian ethnic groups in California. American Journal of Public Health. 2010; 100(5):888-895. [PubMed: 20299644]

Gee GC, Spencer MS, Chen J, Yip T, Takeuchi DT. The association between self-rated racial discrimination and 12-month DSM-IV mental disorders among Asian Americans nationwide. Social Science \& Medicine. 2007; 64(10):1984-1996. [PubMed: 17374553]

Gee GC, Walsemann KM, Takeuchi DT. English proficiency and language preference: testing the equivalence of two measures. American Journal of Public Health. 2010; 100(3):563-569. [PubMed: 19696376]

Gordon, MM. Assimilation in American life: The role of race, religion, and national origins. New York, NY: Oxford University Press; 1964.

Hahm HC, Ozonoff A, Gaumond J, Sue S. Perceived discrimination and health outcomes: a gender comparison among Asian Americans nationwide. Women's Health. 2010; 20(5):350-358.

Hall M, Farkas G. Does human capital raise earnings for immigrants in the low-skill labor market? Demography. 2008; 45(3):619-639. [PubMed: 18939664]

Heeringa SG, Wagner J, Torres M, Duan N, Adams T, Berglund P. Sample designs and sampling methods for the collaborative psychiatric epidemiology studies (CPES). International Journal of Methods in Psychiatric Research. 2004; 13(4):221-240. [PubMed: 15719530]

Huang SL, Spurgeon A. The mental health of Chinese immigrants in Birmingham, UK. Ethnicity and Health. 2006; 11(4):365-387. [PubMed: 17028082]

Hwang WC, Myers HF. Major depression in Chinese Americans: the role of stress, vulnerability, and acculturation. Social Psychiatry and Psychiatric Epidemiology. 2007; 42(3):189-197. [PubMed: 17235440]

Jasso G. Migration and stratification. Social Science Research. 2011; 40(5):1292-1336.

Kessler RC, Mickelson KD, Williams DR. The prevalence, distribution, and mental health correlates of perceived discrimination in the United States. Journal of Health and Social Behavior. 1999; 40(3):208-230. [PubMed: 10513145]

Kim CJ. The racial triangulation of Asian Americans. Politics and Society. 1999; 27(1):105-138.

Kim G, Loi CXA, Chiriboga DA, Jang Y, Parmelee P, Allen RS. Limited English proficiency as a barrier to mental health service use: a study of Latino and Asian immigrants with psychiatric disorders. Journal of Psychiatric Research. 2011; 45(1):104-110. [PubMed: 20537658]

Kim SY, Wang Y, Deng S, Alvarez R, Li J. Accent, perpetual foreigner stereotype, and perceived discrimination as indirect links between English proficiency and depressive symptoms in Chinese American adolescents. Developmental Psychology. 2011; 47(1):289-301. [PubMed: 21244164]

Kim G, Worley CB, Allen RS, Vinson L, Crowther MR, Parmelee P, Chiriboga DA. Vulnerability of older Latino and Asian immigrants with limited English proficiency. Journal of the American Geriatrics Society. 2011; 59(7):1246-1252. [PubMed: 21718269] 
Leu J, Yen IH, Gansky SA, Walton E, Adler NE, Takeuchi DT. The association between subjective social status and mental health among Asian immigrants: investigating the influence of age at immigration. Social Science \& Medicine. 2008; 66(5):1152-1164. [PubMed: 18191317]

Mossakowski K. Coping with perceived discrimination: does ethnic identity protect mental health? Journal of Health and Social Behavior. 2003; 44(3):318-331. [PubMed: 14582311]

Mui AC, Kang SY, Kang D, Domanski MD. English language proficiency and health-related quality of life among Chinese and Korean immigrant elders. Health and Social Work. 2007; 32(2):119127. [PubMed: 17571645]

Mulvaney-Day NE, Alegria M, Sribney W. Social cohesion, social support, and health among Latinos in the United States. Social Science \& Medicine. 2007; 64(2):477-495. [PubMed: 17049701]

Perez DJ, Fortuna L, Alegria M. Prevalence and correlates of everyday discrimination among US Latinos. Journal of Community Psychology. 2008; 36(4):421-433. [PubMed: 19960098]

Ponce NA, Hays RD, Cunningham WE. Linguistic disparities in health care access and health status among older adults. Journal of General Internal Medicine. 2006; 21(7):786-791. [PubMed: 16808783]

Rivera FI, Guarnaccia PJ, Mulvaney-Day N, Lin JY, Torres M, Alegria M. Family cohesion and its relationship to psychological distress among Latino groups. Hispanic Journal of Behavioral Sciences. 2008; 30(3):357-378. [PubMed: 19444326]

Rodriguez N, Myers HF, Mira CB, Flores T, Garcia-Hernandez L. Development of the multidimensional acculturative stress inventory for adults of Mexican origin. Psychological Assessment. 2002; 14(4):451-461. [PubMed: 12501570]

Shi L, Lebrun LA, Tsai J. The influence of English proficiency on access to care. Ethnicity \& Health. 2009; 14(6):625-642. [PubMed: 19953393]

Stanton-Salazar RD, Dornbusch SM. Social capital and the reproduction of inequality: information networks among Mexican-origin high school students. Sociology of Education. 1995; 68(2):116135.

Tang H, Shimizu R, Chen MS. English language proficiency and smoking prevalence among California's Asian Americans. Cancer. 2005; 104(12 Suppl):2982-2988. [PubMed: 16276539]

Torres L. Predicting levels of Latino depression: acculturation, acculturative stress, and coping. Cultural Diversity and Ethnic Minority Psychology. 2010; 16(2):256-263. [PubMed: 20438164]

Torres L, Ong A. A daily diary investigation of Latino ethnic identity, discrimination, and depression. Cultural Diversity and Ethnic Minority Psychology. 2010; 16(4):561-568. [PubMed: 21058819]

Uba, L. A postmodern psychology of Asian Americans: Creating knowledge of a racial minority. Albany, NY: State University of New York Press; 2002.

Vega, WA.; Gil, AG. Drug use and ethnicity in early adolescence. New York: Plenum Press; 1998.

Vega, WA.; Zimmerman, R.; Gil, A.; Warheit, GJ.; Apospori, E. Acculturation strain theory: Its application in explaining drug use behavior among Cuban and non-Cuban Hispanic youth. In: De La Rosa, MR.; Adrados, JLR., editors. Drug abuse among minority youth: Advances in research and methodology. Rockville, MD: National Institute of Drug Abuse; 1993. p. 144-166.

Walton E, Takeuchi DT. Family structure, family processes, and well-being among Asian Americans: considering gender and nativity. Journal of Family Issues. 2010; 31(3):301-332.

Walton E, Takeuchi DT, Herting JR, Alegria M. Does place of education matter? Contextualizing the education and health status association among Asian Americans. Biodemography and Social Biology. 2009; 55(1):30-51. [PubMed: 19835099]

Williams DR, Yu Y, Jackson JS, Anderson NB. Racial differences in physical and mental health: socioeconomic status, stress, and discrimination. Journal of Health Psychology. 1997; 2(3):335351. [PubMed: 22013026]

Williams, DR.; Spencer, MS.; Jackson, JS. Self, social identity, and physical health. Contrada, RJ.; Ashmore, RD., editors. New York: Oxford University Press; 1999. p. 71-100.

Yip T, Gee GC, Takeuchi DT. Racial discrimination and psychological distress: the impact of ethnic identity and age among immigrant and United States-born Asian adults. Developmental Psychology. 2008; 44(3):787-800. [PubMed: 18473644] 
Yoo HC, Gee GC, Takeuchi DT. Discrimination and health among Asian American immigrants: disentangling racial from language discrimination. Social Science \& Medicine. 2009; 68(4):726732. [PubMed: 19095340]

Zeng Z, Xie Y. Asian-Americans' earnings disadvantage reexamined: the role of place of education. American Journal of Sociology. 2004; 109(5):1075-1108. 


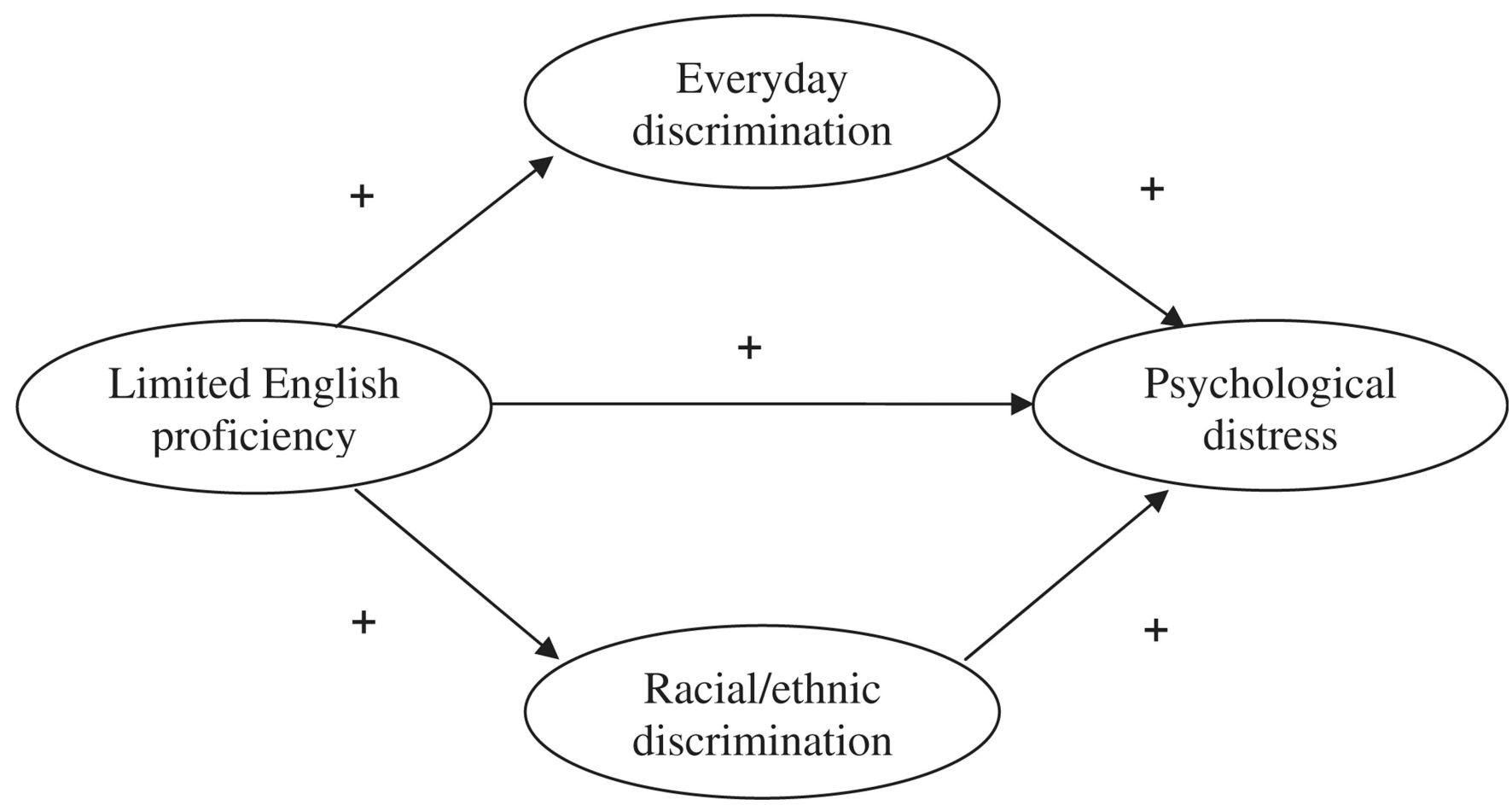

Fig. 1.

Conceptual model of relationships among limited English proficiency, everyday discrimination, racial/ethnic discrimination, and psychological distress. 


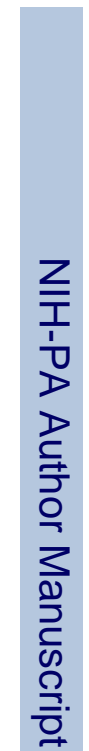

Zhang et al.

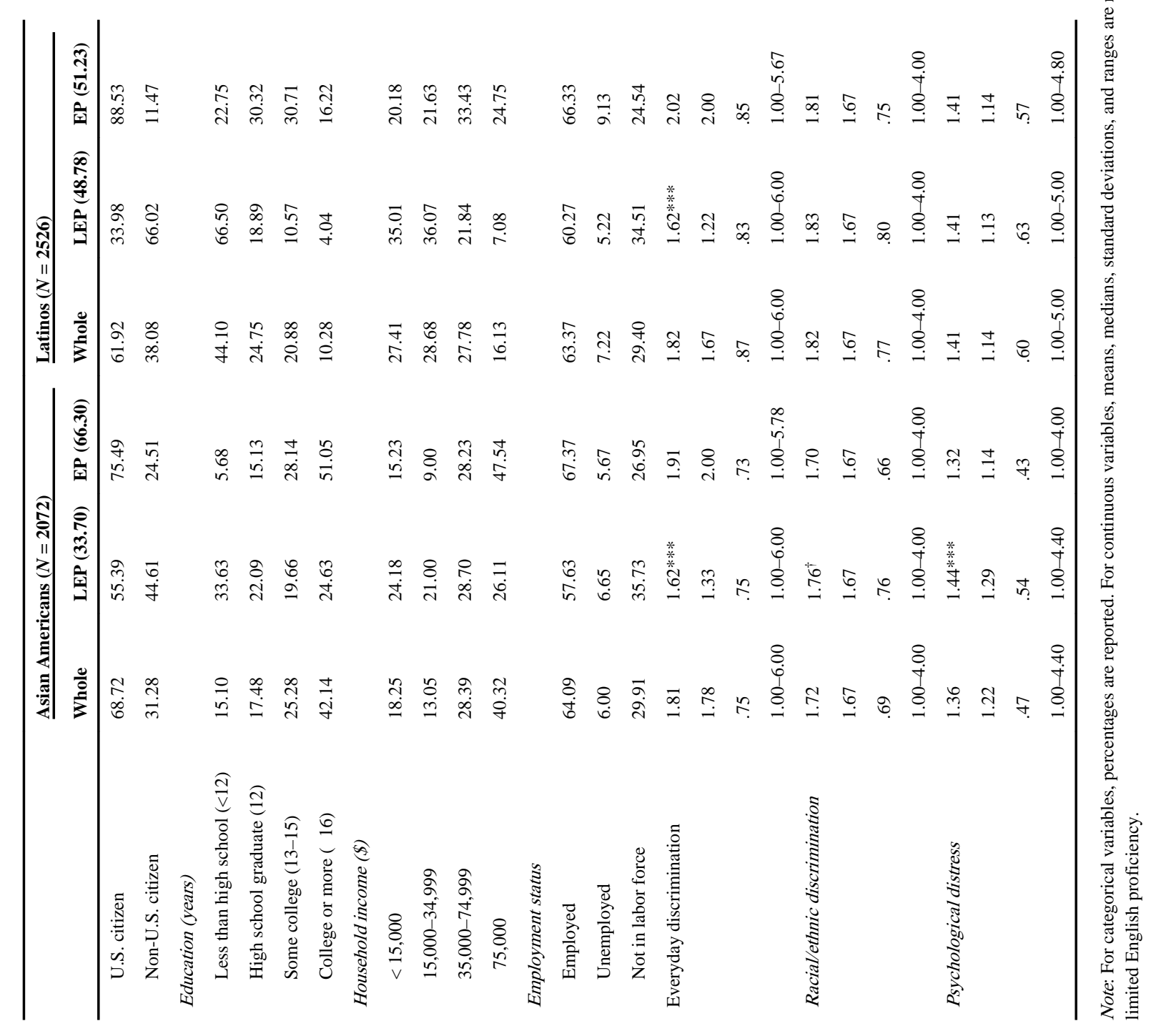




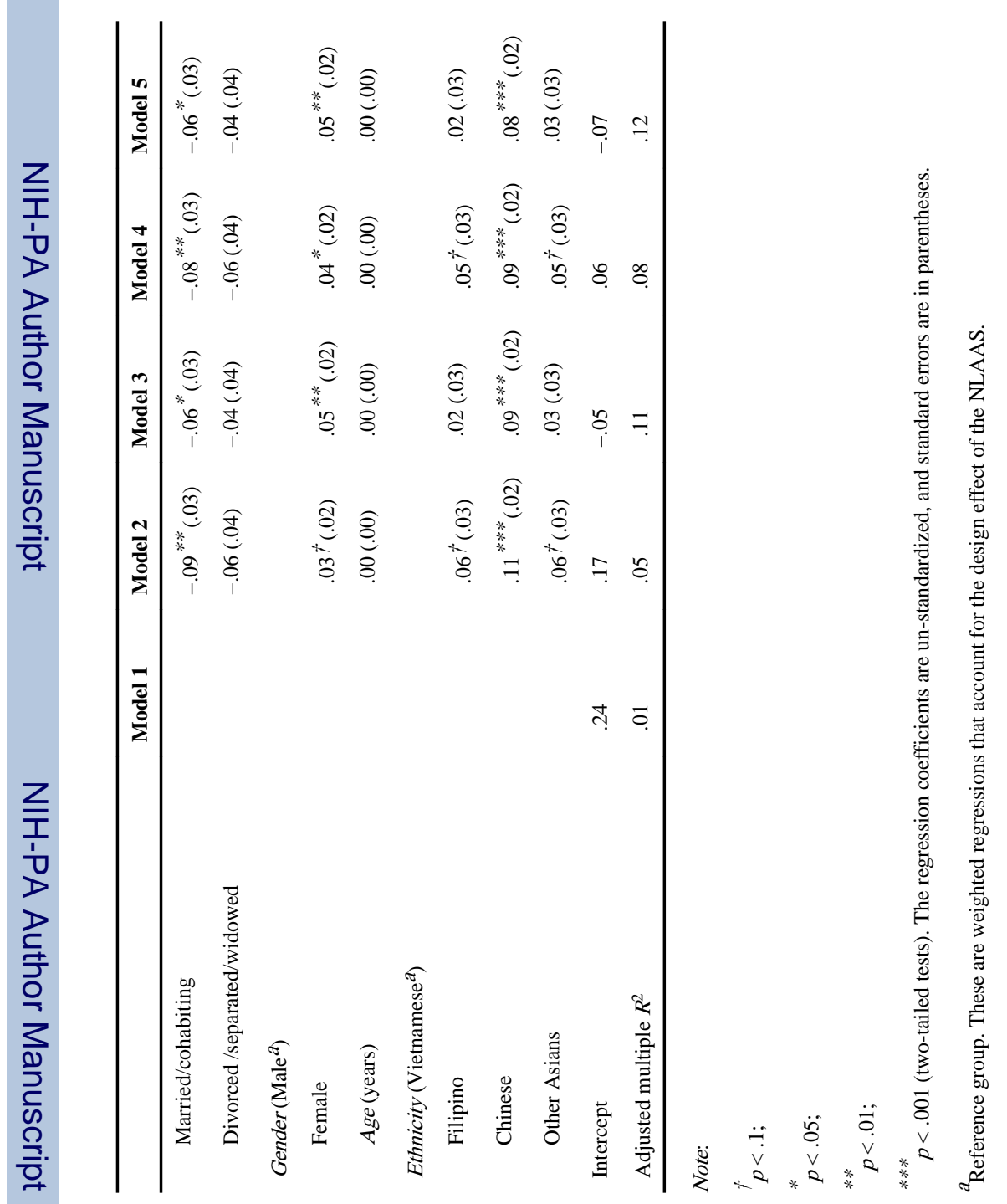

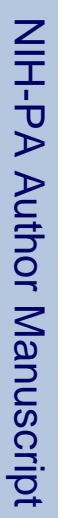




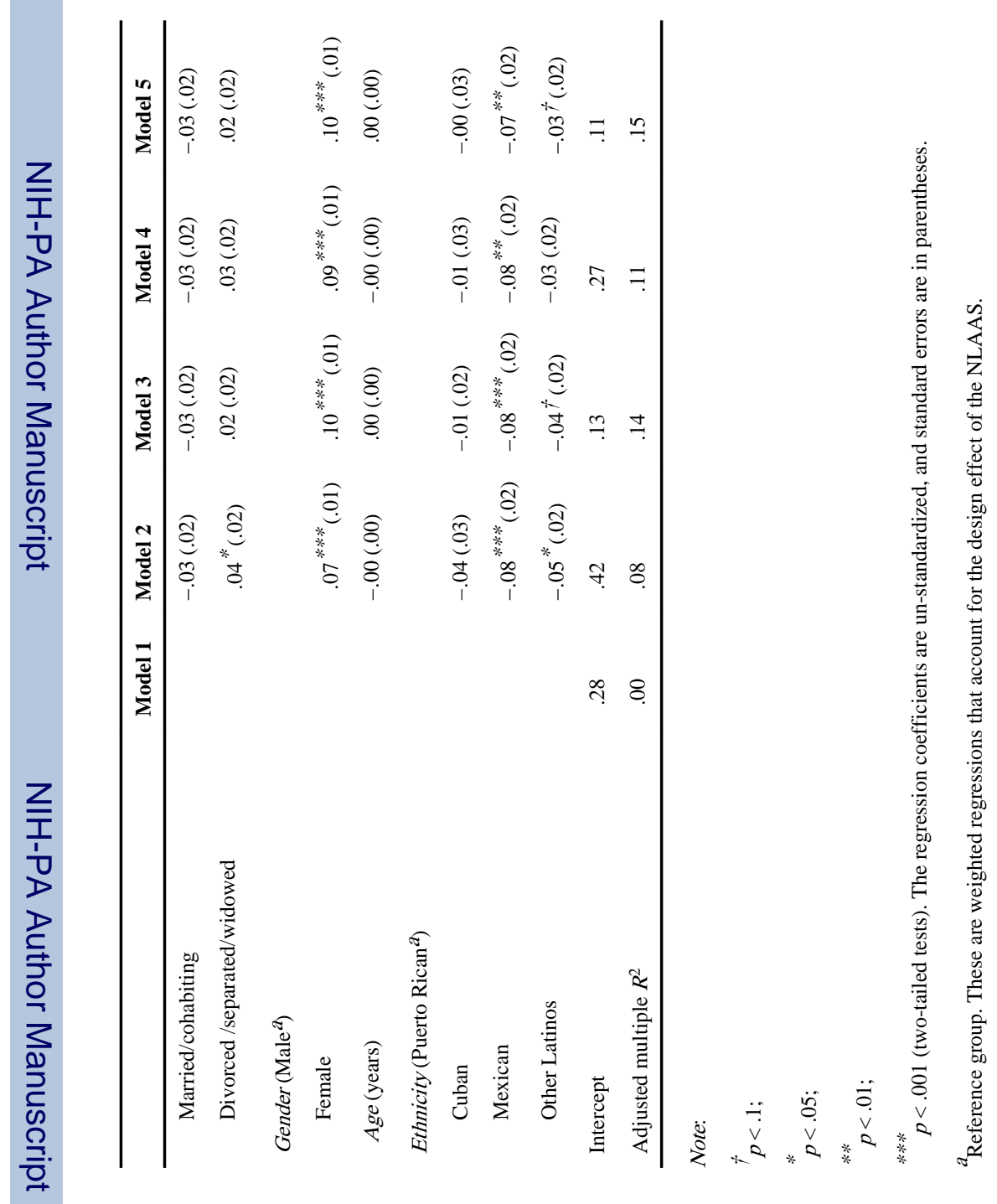

